\title{
Give full play to the role of $M$ station and promote the new normal of vehicle emission pollution control
}

\author{
Anke Yang* \\ Jiaozuo Road Transport Service Center 454003
}

Keywords: M station, I / M system, positive role of $M$ station, new normal of maintenance and management.

\begin{abstract}
With the rapid growth of car ownership in use, vehicle emissions have become one of the main sources of urban air pollution. In view of the problems existing in the maintenance and treatment of vehicle emission pollution, this paper puts forward the enthusiasm and necessity of speeding up the establishment of compulsory maintenance station (M station), adheres to the road of realizing practice, and combines with the practical experience of vehicle emission control in Jiaozuo City, puts forward the practical path of the new normalization management of vehicle emission compulsory maintenance, creatively promotes the treatment of vehicle emission Career development. It is of great significance to solve the more and more outstanding vehicle exhaust pollution.
\end{abstract}

\section{Preface}

At present, the I / M system implemented in our country is a system which can restore the emission performance of the vehicles in use and meet the requirements of relevant standards through regular inspection and spot check of the emission performance of the vehicles in use and maintenance and treatment of the vehicles with excessive emission. I means inspection, and $\mathrm{M}$ means maintenance. Station $\mathrm{M}$ is not only a vehicle emission maintenance and treatment station, but also a business enterprise that undertakes the maintenance and treatment of vehicles with excessive emission pollution in accordance with relevant laws. That is to say, the maintenance enterprise in line with station $\mathrm{M}$, after the maintenance and treatment of the vehicles with emission pollution, will issue a fair conclusion after the inspection of station I is qualified. The "use, detection, governance and supervision" of motor vehicles is the real "closed-loop management" of vehicle detection governance.

Jiaozuo, which borders Taihang in the north and the Yellow River in the south, is a city with coal, chemical industry and other industries as the main guide transitioning to tourism. It is one of the air pollution transmission channels in Beijing, Tianjin and Hebei. The special geographical conditions in front of the mountain cause serious air pollution, which

\footnotetext{
*Corresponding author: jtysfzx@163.com
} 
has become the focus of social attention. However, there are more than 150000 passing vehicles and more than 50000 self owned large-scale diesel operating vehicles in Shanxi every day. The emission pollution of the vehicles in use is one of the main sources of air pollution, which attracts people's attention. The situation is very serious. Therefore, it is an urgent task to do a good job in the construction of station M, implement the I / M system, and strengthen the maintenance and treatment of vehicle emission pollution. According to the guidance on promoting the transformation and upgrading of automobile maintenance industry and improving the service quality jointly issued by the Ministry of transport, the Ministry of environmental protection, the Ministry of public security and other ten ministries and commissions in 2014, $17 \mathrm{M}$ stations were creatively built in 2017, and some results were achieved through operation, which was investigated and demonstrated by the Ministry of environmental protection and the Academy of communications. However, there are problems such as some departments that are not connected, without supporting systems and laws and regulations support and technology nonstandard make vehicle emission pollution control in an abnormal state. By the beginning of 2019, 11 departments such as the Ministry of ecological environment issued the action plan for tackling the pollution of diesel trucks, which requires that the vehicle emission detection and compulsory maintenance system should be fully established and improved by the end of the year, and 9 M stations should be built according to the high standard of 2019 maintenance industry group standard technical conditions for the construction of $\mathrm{M}$ stations for the maintenance and treatment of vehicle emission, which standardizes the regular emission of motor vehicles in use Inspection, supervision, sampling and compulsory maintenance to make the vehicles with excessive emission meet the requirements of relevant emission standards. The new normal of correct use, strict testing, innovative supervision and standardized governance has been realized. Thoroughly solve the problems of policies and regulations, data sharing, network management, and constantly improving technical level.

Through unremitting efforts, we adhere to the road of realizing practice, and creatively promote the development of motor vehicle emission control.

\section{Positive role of $M$ station construction}

\subsection{The construction of $M$ station is the requirement of "air pollution prevention and control" for vehicle emission control}

"Air pollution has become an inescapable reality in the life of urban residents all over the world.". After the reform and opening up, China has experienced the rapid development of "getting rich" for decades. Although it has created huge wealth for us, industrial civilization and urban development have made great progress, but it has discharged billions of tons of waste gas and waste into the atmosphere, bringing great disasters to human beings and the environment. Therefore, the prevention and control of air pollution is related to the vital interests of the masses, and is of great significance to improve the air quality of the city and the well-being of the masses. In recent years, with the increasing number of vehicles in use in China, the urban air pollution has been transformed from the coal smoke type to the mixed type of coal smoke and vehicle exhaust. The vehicle emission has become an important source of air pollution. The PM10 and other particulate matters produced by the emission are higher, and the NOx produced by the emission is far higher than that in Europe and America. In China, there are 325 million motor vehicles, of which 300 million are diesel freight vehicles. The pass rate of regular emission inspection of diesel freight vehicles is about $85 \%$. Some of the over standard motor vehicles have not been repaired and treated. The problem of over standard emission has not been fundamentally solved by 
means of temporary replacement of motor vehicle pollution control devices, falsification of inspection results and other fraudulent methods. The in use vehicle inspection and maintenance system (I / M system), which is widely implemented in developed countries and regions such as Europe, the United States and Japan, has realized closed-loop management of vehicle exhaust emission control and significantly improved the in use vehicle emission qualification rate. China's "three year action plan to win the blue sky defense war" has clearly defined the goal, and the "action plan to tackle diesel truck pollution" has clearly defined the comprehensive establishment of vehicle emission inspection and compulsory maintenance system. According to expert analysis, the implementation of I / M system will bring at least $20 \%$ reduction in pollutant emissions. Therefore, it is imperative to win the blue sky defense battle, accelerate the construction of $\mathrm{M}$ station and strengthen the maintenance and treatment of vehicle emissions.

\section{2 $\mathrm{M}$ station construction enriches and improves the existing maintenance system}

At present, the main contents of the current maintenance system in China are basic conditions, equipment and facilities, technical standards, employees, service quality, etc. the newly issued traffic standard "technical conditions for the construction of automobile emission pollution maintenance and treatment station (M station)" fully conforms to the contents of the maintenance system. It not only enriches and improves the existing maintenance system, but also has the maintenance and treatment of excessive vehicle emissions Clear legal status. That is to say, $M$ station has basis, standard and method. At the same time, it is decided to put the construction of $\mathrm{M}$ station in the operation of class I and class II maintenance enterprises in the regulations on the management of motor vehicle maintenance, which is equivalent to the addition of detection and diagnosis equipment such as the detection and diagnosis system for the treatment of excessive emission of vehicles in use, the diagnostic system for the emission of pollutants by the working condition method, smoke detector, fuel injector detection and cleaning analyzer, carbon deposition removal equipment, DPF ash removal equipment, SCR Cleaning equipment and other maintenance and management equipment, staffing and other aspects are also fully in line with the maintenance system construction. This paper puts an end to the construction of $\mathrm{M}$ station in the three types of maintenance enterprises, and explains that the treatment of vehicle emission exceeding the standard can only be achieved through the maintenance under working conditions, which is impossible for the three types of maintenance enterprises.

\subsection{The construction of $M$ station is the basic condition to realize the "closed-loop management" of vehicle emission control}

The construction of automobile maintenance and management station ( $\mathrm{M}$ station) is the basic element to realize the "closed-loop management" of vehicle emission control. In terms of vehicle emission pollution control, station I and station $\mathrm{M}$ depend on each other. If station I detects any problem, station $\mathrm{M}$ will treat it. If station $\mathrm{M}$ meet the requirements after treatment, depends on the conclusion of station I. Not every car owner is willing to consciously accept the treatment of $\mathrm{M}$ station on the premise of knowing or not about the emission exceeding standard. It is through vehicle inspection and detection, fixed-point detection, mobile detection, etc. to find out the emission exceeding standard vehicles, directly transfer their data to the vehicle traffic, environmental protection inspection and supervision system, and standardize the program through the network software. These vehicles must go to $M$ station for treatment and data transmission after passing the treatment. The vehicle security inspection and comprehensive inspection can only be 
carried out after the vehicle is unlocked at the supervision platform and qualified in the environmental inspection again. At present, it is a process of transformation from unconsciousness to consciousness. Only by relying on each other and strengthening supervision can we achieve closed-loop management and achieve the effect of compulsory maintenance management.

\subsection{M station operation is an inevitable requirement to improve vehicle recovery technology and reduce exhaust pollution}

In the process of continuous use of the automobile, it is easy to produce mechanical wear and aging, so that the emissions and fuel consumption exceed the standard seriously. How to maintain and manage, save energy and reduce emissions, and restore the technical condition of the vehicle? Only through the maintenance and treatment of M station, can the technical condition be restored and the exhaust pollution be reduced.

Gasoline engine is checked by the automobile emission analyzer equipped in station $\mathrm{M}$, and various indexes of carbon monoxide (CO), hydrocarbon (HC), nitrogen oxide (NO), sulfide (SO) are analyzed to see whether the working condition of carburetor is good, which is easy to cause the mixture to be too thick or too thin, and whether there is too much carbon deposition in spark plug and engine combustion chamber, which is easy to cause no point In case of fire or spontaneous combustion, disordered ignition, abnormal work, reduced output power and increased blowdown, cleaning or replacement shall be adopted; in case of gas channeling caused by serious wear of cylinder and piston ring, maintenance and treatment shall be carried out in the maintenance enterprise affiliated to station $\mathrm{M}$; in case of failure of three-way catalytic converter of tail gas treatment system and out of control problem of sensor, cleaning and replacement shall be carried out.

Diesel engine, due to the low ignition point of diesel, the gas compression to a certain extent, will explode and burn, and complete the working principle of inlet, pressure, operation and exhaust, which is easy to cause incomplete and incomplete combustion, resulting in low combustion efficiency. In addition, the low cetane number of diesel fuel, long combustion delay period, is easy to cause a large amount of carbon deposition in the combustion system and exhaust system, large black smoke, and increased pollution. Only by adjusting the oil pump can The problem of black smoke can not be solved by changing the fuel supply. It is analyzed that the main pollutant is particulate matter (PM) nitrogen oxide (NO), which can only be treated by maintenance in M station. During the treatment, the fuel injection condition of the fuel injector and the cylinder wear pressure shall be checked first, and then the exhaust control device shall be mainly checked: DOF (diesel particulate filter) can intercept $70 \%-90 \%$ PM particles in the exhaust gas to see whether the filter made of metal fiber felt is blocked, and whether it can play a normal role. If the blockage is serious, the dust shall be removed and cleaned by special equipment; SCR system (catalyst) It is a treatment process of NOx emission from diesel vehicle exhaust, i.e. purification of nitrogen oxide, that is, under the action of catalyst, injection of reducing agent ammonia or urea to reduce $\mathrm{NOx}$ in exhaust gas to $\mathrm{N} 2$ and $\mathrm{H}_{2} \mathrm{O}\left(\mathrm{NH}_{3}+\mathrm{NOx} \rightarrow \mathrm{N}_{2}+\right.$ $\mathrm{H}_{2} \mathrm{O}$ ). During treatment, not only the SCR system should be cleaned, but also the number and quality of urea, working condition of urea pump, electric control device and other problems should be detected and maintained one by one.

At the same time, we should severely crack down on individual $\mathrm{M}$ stations, use temporary replacement of pollution control devices and other fraudulent methods to help motor vehicle owners pass the emission test. 


\subsection{Construction and operation of $M$ station is a long-term mechanism for vehicle emission control}

According to the data of relevant departments, at present, there is one vehicle for every four people in China, most of which exist in large and medium-sized cities. According to the data of Beijing Environmental Protection Bureau at the end of 2015, $\mathrm{PM}_{2.5}$ comes from motor vehicles accounting for $31 \%$ of local emission sources. The share rate of vehicle emission to urban air pollution in China is as high as $20 \%-60 \%$, so the implementation of $\mathrm{M}$ station system is imminent. The construction of $\mathrm{M}$ station is a long-term mechanism. First, it can carry out vehicle emission pollution control in combination with maintenance vehicles; second, road transport operators can carry out vehicle emission pollution control according to driving mileage and technical conditions; third, it can carry out emission pollution control in combination with comprehensive security inspection. The law of the people's Republic of China on the prevention and control of air pollution and the technical conditions for the construction of automobile emission pollution maintenance and treatment station (M station) provide policy basis and technical support for our long-term and effective treatment. Through the establishment of coordination mechanism between environmental protection and transportation departments, a regulatory system for the treatment of automobile exceeding the standard is formed, which is conducive to improving the comprehensive treatment capacity. Only by adhering to the long-term mechanism can the political task of air pollution control be completed.

\section{Jiaozuo practice of promoting the realization of the new normal of vehicle emission control}

According to the role of $\mathrm{M}$ station and the requirements of "closed-loop management", Jiaozuo has achieved the correct use of motor vehicles, strict inspection, strengthened supervision, standardized construction, standardized maintenance and governance through active and creative efforts, and really promoted the realization of the new normal state of vehicle emission control.

\subsection{Strive to improve the correct use skills of drivers and promote the new normal of vehicle emission pollution control}

In terms of improving the professional skills of drivers, we strictly implement the requirements of vehicle technology management regulations, vehicle driver training management regulations and training program, insist on educating drivers in driver training, job qualification training and safety training, and pay attention to driving while selecting safe and reliable, green environmental protection, energy conservation and emission reduction vehicles suitable for transportation tasks Training for correct use of personnel. Correct driving is the main method of energy conservation and emission reduction, such as how to drive at a moderate speed, how to slow down and accelerate, how to use the clutch and brake pedal correctly, how to grasp the shift timing, etc.; correct use of fuel is the basis of ensuring the normal emission of vehicles, it is necessary to strictly implement the vehicle use instruction, resolutely put an end to the use of substandard fuel, how to use No.0 and No.10 diesel oil, and how to use No. 0 diesel can be used in Henan Province, but it is absolutely not allowed in Northeast China. Sometimes, it depends on the environmental conditions of vehicle operation; qualified urea for diesel vehicle must be used, and the urea tank will automatically spray out tail gas treatment liquid, which will generate oxidation-reduction reaction in SCR catalytic reaction tank, and generate pollution-free nitrogen and water vapor. Due to the unqualified fuel and urea, the exhaust emission is 
unqualified, which can be handed over to the on-board OBD real-time monitoring. This is the most effective way to reduce the emission of particulate matter.

\subsection{Combining the "three checks and one" to implement the construction of station I and promote the new normal of vehicle emission pollution control}

In order to reduce the transportation cost and reduce the burden of transportation operators, the state has decided to comprehensively reform the inspection work of freight vehicles, and has decided to combine the annual inspection (safety technology inspection), annual inspection (comprehensive performance inspection) and environmental inspection (exhaust emission inspection) of operating vehicles into "three inspections in one". The municipal road transport administration actively held the "three inspections in one" work promotion meeting of the city's freight vehicles, and issued the notice on Forwarding the detailed rules for the implementation of accelerating the reform of inspection and detection of road freight vehicles. In the reconstruction and new stations, in order to effectively control and control the vehicles with excessive emissions, the construction of station I should be put first. In the reform, it has overcome the following problems: "first, the comprehensive inspection institutions owned by the county and city transportation management departments protect the interests of their own units; second, they are faced with the problems of the survival of their own secondary institutions and the layoff of staff; third, they are used to relying on administrative functions to protect the old inspection stations, no investment, no leading work, fear of examination and approval trouble and relying on watching; fourth, some inspection stations have adapted to the situation The problems such as single management mode and unwillingness to multi management are often heard as swearing and complaining. We adhere to the work of policy interpretation, publicity and guidance, strive to get everyone's understanding, open the testing market, and break the monopoly management system. According to the requirements of the action plan for tackling the pollution of diesel trucks, the construction of station I was completed by the end of September 2019. Up to now, 22 inspection and testing institutions have been newly built and rebuilt in the city, all of which have met the "three inspections in one" standard, realized the networking operation, and ensured that the operation of station $\mathrm{I}$ is the normalization of vehicle emission detection.

\subsection{Strengthen the construction and application of "network supervision system" and promote the new normal of vehicle emission pollution control}

At present, the city's network supervision system includes: first, the "three checks in one" has been connected to the transportation administration network through the communication center of the Ministry of communications, which can monitor the conclusions of station I in real time in the communication center. When handling the annual review procedures, you can see whether it has passed the inspection of station I, otherwise, the annual review cannot be carried out. Second, for vehicles with excessive exhaust pollution, basic information and maintenance records can be queried in the vehicle maintenance electronic health archive network of the transportation department during maintenance and treatment. After maintenance and treatment, information data can be uploaded to the vehicle maintenance electronic health archive network and connected with the supervision network of the environmental protection department. The third is to establish a network system of vehicle emission supervision. The municipal vehicle emission monitoring center took the lead in establishing a management system of vehicle environmental protection inspection in our province, standardizing the vehicle inspection procedures in software and establishing a two-level audit (county-level Ecological 
Environmental Protection Bureau audit and City Monitoring Center audit) mode, which greatly reduced the phenomenon of non-standard inspection report data. The "blacklist" system shall be implemented for the unqualified vehicles, and the environmental protection department shall inform the transportation department to supervise the maintenance and management. The fourth is the installation of on-board OBD. By using the "on-board terminal + monitoring platform + big data analysis" OBD commercial vehicle brain service and the networking of transportation and environmental protection departments, the functions of real-time data collection, network transmission, real-time monitoring, data storage, etc. are realized, meeting the requirements of closed-loop management of inspection and treatment. For the motor vehicles that fail to pass the regular emission inspection, the vehicle emission inspection agency shall notify the owner (or user) of the motor vehicles to carry out the re inspection at the same I station after the maintenance. The enterprises dealing with the maintenance of the motor vehicle emission exceeding the standard shall carry out the maintenance according to the emission inspection results obtained from the vehicle emission inspection information system. Through the construction and application of "network supervision system", the normalization of closed-loop management of vehicle emission control and detection is realized, which not only reduces the contradiction between the owner and the supervision department, dispels the owner's doubt and distrust of the supervision department, but also controls the effective maintenance and management of station $\mathrm{M}$, and solves the fraud in the environmental protection inspection procedure. That is to say, it is the most effective measure to realize the closed-loop management to use the network system for supervision and development.

\subsection{High standard construction and good operation of $M$ station to promote the new normal of vehicle emission pollution control}

\subsubsection{We will work together to give strong support}

In order to win the blue sky defense battle, effectively control the exhaust pollution of motor vehicles in use, and strengthen the treatment of motor vehicle emission in our city. Wang Shuren, director of the Transportation Bureau, clearly put forward at the meeting of the implementation of the action plan of diesel truck pollution control in the transportation system that "diesel truck pollution control is the central work of vehicle technology management, and we must win the battle of diesel truck pollution control, which is the political task of large gas pollution control work". Comrade Han Guoqing, director of Jiaozuo Ecological Environment Bureau, once served as the leader of Jiaozuo traffic police detachment. He was concerned about environmental protection and cars. According to the three-year action plan to win the blue sky defense battle of the State Council and the action plan for diesel truck pollution treatment of 11 departments including the Ministry of ecological environment ([2018] No. 179), he immediately asked the vehicle emission monitoring center to contact the transportation management department, jointly issued the notice on the construction of motor vehicle exhaust maintenance and treatment station $(\mathrm{M}$ station) (JHF [2019] No. 52), held regular meetings for many times, clarified the specific requirements and regulations for the construction of $M$ station, studied and solved the construction and development problems of $\mathrm{M}$ station, and made the motor vehicle emission monitoring center strive for 500000 yuan for the construction of $\mathrm{M}$ station through many positive efforts Financial support for station construction. The municipal road transportation administration bureau has completed the construction task of $\mathrm{M}$ station based on its own duty and creative work. It can be said that the leaders of the two departments attach importance to support is the fundamental way for us to complete the task of station building quickly and effectively. 


\subsubsection{Jointly check and build M station}

According to the requirements of the notice on the construction of motor vehicle emission maintenance and treatment station ( $\mathrm{M}$ station) and the technical conditions for the construction of motor vehicle emission pollution maintenance and treatment station (M station), the construction of $\mathrm{M}$ station in the whole city is regulated based on the principles of voluntary application, reasonable distribution, standardized construction and big data sharing. Put forward the requirements of construction standards, facilities and equipment, employees, management system, etc., at the same time, make clear provisions on the construction procedure of $\mathrm{M}$ station, adhere to the principle of approval before construction and use. In June 2019, the city accepted 25 maintenance enterprises applying for the construction of $\mathrm{M}$ station, which were investigated and understood by the municipal motor vehicle emission monitoring center and the road transport administration, and insisted on the following: first, technical evaluation and expert review; second, the number of construction enterprises should be compatible with the local motor vehicle ownership and the maintenance requirements of over standard emission vehicles; third, they can be connected with the transportation and environmental protection departments; fourth, they can be connected according to the Based on the national automobile maintenance electronic health record system, 9 Maintenance Enterprises above class II were finally determined to build $\mathrm{M}$ station. The maintenance enterprises of Wuzhi Hongtai company, as the construction pilot of $\mathrm{M}$ station, have achieved "four unification: unification of station area, unification of machines and equipment, unification of standard system, unification of personnel training and dressing; three publicity: openness of price, inspection and governance; two specifications: standardization of operation process, standardization of handover procedures; one commitment: signing of quality assurance responsibility commitment". Give the vehicles with substandard emissions a "home", let them "repair" at home, resume "physical strength" and continue to "work". The "home of governance" ensures that the vehicles with substandard emissions in our city can be effectively managed.

\subsubsection{Adhere to standardized governance}

Insist on improving the quality of employees as a breakthrough point, invite experts to carry out professional training to meet the requirements of using equipment, inspection and governance, use system management to restrain people, use standard operation procedures, strictly standard operation procedures, and carry out maintenance and governance according to technical conditions. Jiaozuo transportation management department strictly urges station $\mathrm{M}$ to accurately diagnose and reasonably maintain according to the regulations on management of vehicle maintenance, technical standards and specifications, vehicle emission inspection report and information recorded by on-board diagnosis system, so as to prevent minor illness overhaul or excessive maintenance, and to prevent replacing the real fault diagnosis and maintenance of vehicles with simple replacement of emission control components. The pilot $\mathrm{M}$ station in our city is put into operation first, and it has been put into operation in September 2019. By the end of March this year, 3957 vehicles with emission pollution have been repaired and treated. In terms of maintenance and treatment, the principle of inspection before treatment and cleaning before replacement has been adhered to, and the maintenance and treatment method of determining parts has been analyzed and determined strictly according to the classification of inspection results. For gasoline vehicles, if no seriously exceeds the standard, it may be that the oil-gas mixture ratio is too thin, the intake system, the engine combustion chamber has too much carbon deposition, there is spontaneous combustion, the three-way catalytic converter and oxygen sensor fail. After using high-efficiency cleaner, add repair agent to repair, generally 
cleaning the three-way catalytic converter or replacing the oxygen sensor. For diesel vehicles, if NOx exceeds the standard, problems in SCR system (catalytic converter) shall be solved, and problems in DPF (particle filter) shall be solved if PM10 exceeds the standard. Only in this way can we solve the problem of over standard emissions one by one, and form a new normal of maintenance management.

$\mathrm{Wu} \mathrm{Bo}$, an environmental protection science and technology expert who is guiding the construction and training of $\mathrm{M}$ station, said: "at present, the construction of $\mathrm{M}$ station in Jiaozuo City has been in the forefront of Henan Province and the whole country. After the diesel trucks with black smoke meet the standards, the air pollution emissions can be reduced by $90 \% . "$. It can be said that Jiaozuo traffic people have overcome many difficulties in the battle of air pollution prevention and control, and have achieved great political, social and environmental benefits. The construction and operation of $\mathrm{M}$ station is a new normal for the treatment of vehicle emission pollution in Jiaozuo City and the implementation of I / M system.

\section{Reference}

1. The state council, Three year action plan to win the blue sky defense war, 2018

2. Ministry of ecological environment, Action plan for diesel truck pollution control, 2018

3. Maintenance industry group standard, Technical conditions for the construction of automobile emission pollution maintenance and treatment station (M station), 2019

4. Ministry of ecological environment, Notice on the establishment and implementation of vehicle emission inspection and compulsory maintenance system, 2019 